more patient undergoing dialysis and on the waiting list for a cadaver organ.

Royal Postgraduate Medical School

Hammersmith Hospital,

London W'12 0NN

1 Macdougall IC, Hutton RD, Cavill I, Coles GA, Williams JD. Treating renal anaemia with recombinant human erythropoietin: practical guidelines and a clinical algorithm. Br.Med 7 1990;300:655-9. (10 March.)

2 Opelz G. Improved graft survival in nontransfused recipient. Transplant Proc 1987;19:149-52.

\section{Absorption of irrigating solution during transcervical resection of endometrium}

SIR, - Two of the comments made concerning our study of fluid dynamics during endometrial resection' show the false logic of applying the urological principles of transurethral prostate resection to the uterus. These misapprehensions are serious as their unconsidered application would lead to potentially unsafe and ineffective surgery at a time when this form of intervention is fast gaining popularity among gynaecologists and public alike.

Firstly, the question of uterine distension. The correct intrauterine pressure is the minimum pressure that produces adequate distension of the uterine cavity to allow for the identification of landmarks and a clear view during surgery. An irrigation pressure of $60 \mathrm{~cm} \mathrm{H}_{2} \mathrm{O}$ as recommended by Dr T C A Boto and colleagues ${ }^{2}$ may be sufficient to distend the compliant and thin walled bladder during endoscopic prostate resection ${ }^{3}$ but is wholly inadequate in the case of the non-compliant and thick walled uterus. As long ago as 1972 Quinones et al showed that although images of the uterine cavity are possible with a pressure of $40 \mathrm{~mm} \mathrm{Hg}$ $\left(54 \mathrm{~cm} \mathrm{H}_{2} \mathrm{O}\right)$, the pressure must be increased to $100-110 \mathrm{~mm} \mathrm{Hg}\left(136-150 \mathrm{~cm} \mathrm{H}_{2} \mathrm{O}\right)$ to identify the tubal orifices. ${ }^{+5}$ Our experience with intrauterine pressure measurements are broadly similar, some variability being afforded by factors such as uterine size and fibroids. It is of course essential to ensure proper uterine distension during hysteroscopic surgery to reduce the risks of perforation and other accidents as a result of poor visualisation.

The second comment refers to the questions of absorption of irrigant fluid overload, and disturbances in electrolyte concentrations. Analysis of the first 139 procedures showed that the median volume of $1.5 \%$ glycine solution absorbed during endometrial resection was $350 \mathrm{ml}$, with 35 of the patients absorbing more than $500 \mathrm{ml}$ and 11 more than 1 litre. The haemodynamic and biochemical consequences of fluid loads of up to 2 litres were well tolerated by these patients. This was probably a result of the rapid distribution of glycine solution throughout the 15 litres of extracellular water owing to the good cardiac and renal function of our relatively young female subjects, factors that are in contrast with those in most elderly men undergoing prostatic surgery. There is thus no reason to stop surgery once $500 \mathrm{ml}$ of uterine irrigant has been absorbed, as recommended by Dr Boto and colleagues, and leave the patient with the difficult choice between incomplete treatment or readmission and retreatment. Although relevant in only about $8 \%$ of cases, a more realistic approach in otherwise fit patients is to try to complete the procedure as quickly as possible once 1 litre of uterine irrigant has been absorbed and to stop, whatever the stage of surgery, when the fluid deficit is approaching 2 litres, at the same time checking serum electrolyte concentrations and assessing the clinical state of the patient. Such a protocol is not inconsistent with published urological practice ${ }^{t}$ and is certainly more conservative than the management of fluid dynamics during laser ablation of the endometrium.

Other points raised ${ }^{2}$ include the role of tubal loss of uterine irrigant and the use of $1.5 \%$ glycine solution to distend the uterus. Briefly, as reported recently, we have found that prior tubal blockage reduces the amount of uterine irrigant absorbed by the patient by an average of $20 \%(315 \mathrm{ml} v 400 \mathrm{ml})$, an identical value to that quoted by Quinones et al for diagnostic hysteroscopy. ${ }^{5}$ As for the choice of uterine irrigant, which we did not claim is isotonic, the use of $1.5 \%$ glycine solution in urology is traditional and based on the principle of the least amount of a non-electrolyte substance that could be added to distilled water to form a solution that would prevent haemolysis. ${ }^{10}$ Though $1.5 \%$ glycine solution is not the ideal irrigant, it has at least the benefits of experience. We agree, however, that the theoretical advantages of isotonic solutions should be investigated.

ADAM L MAGOS GILLIAN M LOCKWOOD RALF BAUMANN SIR ALEXANDER C TURNBULL JONATHAN D S KAY

University of Oxford,

John Radcliffe Hospital

Oxford OX3 9DU

1 Baumann R, Magos AL, Kay JDS, Turnbull AC. Absorption of glycine irrigating solution during transcervical resection of glycine irrigating solution during transcervical resection

2 Correspondence. Absorption of irrigating fluid during transcervical resection of endometrium. Br Med f 1990;300:748-9. (17 March.)

3 Mitchell JP. The principles of transurethral resection and haemostasis. Bristol: Wright, 1972:139.

4 Quinones RG, Alvarado DA, Aznar RR. Tubal catheterisation applications of a new technique. Am $\mathcal{F}$ Obstet Gynecol 1972;114:674-8

5 Quinones RG. Hysteroscopy with a new fluid technique. In Siegler AM, Lindemann HJ, eds. Hysteroscopy. Principles and practice. Philadelphia: Lippincott, 1984:41-2.

6 Dodson ME. Lithotripsy for renal stone disease. $\mathrm{Br} \mathrm{Med} \mathcal{f}$ 1985;291:1577.

7 Norlen H, Allgen L, Wicksell B. Sorbitol concentrations in plasma in connection with transurethral resection of prostate using sorbitol solution as an irrigating fluid. Scand $\mathcal{F} U$ rol Nephrol 1986;20:9-17

8 Morrison LMM, Davis J. Sumner D. Absorption of irrigating fluid during laser photocoagulation of the endometrium in the treatment of menorrhagia. Br 7 Obstet Gynaecol 1989;96: $346-52$.

9 Magos AL, Baumann R, Turnbull AC. Safety of transcervical endometrial resection. Lancet 1990;335:44

0 Nesbit RM, Glickman SI. Use of glycine as irrigating medium during transurethral resection. F Urol 1948;59:1212-7.

\section{Should pathologists talk to patients?}

SIR, - The report by Drs Stephen R Vallely and J O Manton Mills' and subsequent correspondence raise important issues regarding when patients should be told the results of tests and by which doctor - that is, by the referring clinician or by the clinician who carried out the test. It may come as a surprise that some pathologists are faced with the same dilemma.

Those institutes that are most experienced in fine needle aspiration cytology recommend that the aspirate should be taken by the doctor who also interprets the slides; this is usually the cytopathologist. 'Like some other pathologists in this country, ${ }^{4}$ we follow this recommendation and have for the past year offered a fine needle aspiration service on this basis. We normally ask patients to wait while the slides are stained and examined, and if we reach a confident benign diagnosis we inform the patient. As many of the patients are women with breast lumps this policy eliminates the usually highly anxious wait of up to a week.

Most of our patients are seen in an outpatient setting where the surgeon and nursing staff are available for support, and in these cases patients with malignant disease are also told of the diagnosis unless there is a reason not to. Occasionally we diagnose malignancy in the absence of the referring clinician, and this provides us with a problem. In our experience once the patient knows that we have examined the slides she expects to be told the results and few are worried whether the doctor who tells them is a surgeon or a cytopathologist, provided that they get a rapid and honest answer delivered with tact, and we endeavour to give this. We believe, however, that these patients should see the appropriate referring surgeon as quickly as possible in order to discuss different treatment possibilities.

P C H WATT L CAUGHLEY $M$ VARMA

Department of Cytopathology

Royal Victoria Hospital,

Belfast BT12 6BA

1 Vallely SR, Mills JOM. Should radiologists talk to patients? BrMed f 1990;300:306-6. (3 February.)

Correspondence. Should radiologists talk to patients? Br Med 1990;300:610. (3 March )

3 Hajdu SI, ed. The value and limitations of aspiration cytology in the diagnosis of primary tumours. A symposium. Acta Cytol 1989;33:741-96.

4 Zuk JA, Maudsley G, Zakhour HD. Rapid reporting of fine needle aspiration of breast lumps in outpatients. $\mathcal{F}$ Clin Patho 1989;42:906-11.

\section{Private patients preferring to use NHS facilities}

SIR,-We must thank Dr A C Fairbank and colleagues for reporting what most clinicians have suspected for a long time: that a substantial number of patients using NHS facilities have insurance that would enable them to use the private sector without personal cost. ${ }^{\prime}$ They do this because they are happy with the care in NHS hospitals, especially in specialties such as day surgery, in which the private sector lags far behind. Even if private facilities are available these patients will not choose to use them.

Surely, therefore, what is needed is a way to induce such people to become paying patients in NHS hospitals rather than to steer them towards the private hospitals which would be their second choice. Many would willingly become paying patients for very little in return, having most of what they want already at basic NHS level. A patient of mine illustrated this well when she commented to the unit manager who visited the operating theatre where she was undergoing caesarean section under epidural anaesthesia that couldn't have been better if she had used her BUPA card. Asked why she hadn't done, she replied that she did not know that the option was there.

A way is needed to encourage such patient without making non-paying NHS patients fee second class. The benefit to district hospitals if $10 \%$ of their patients were paying would be considerable.

Hinchingbrooke Hospital,

M J HARE

Cambridgeshire PE18 8N" 1 Fairbank AC, Stapleton SR, Jarrett PEM. Patients with private
health insurance using NHS facilities in preference to private
care. Br Med f 1990;300:719. (17 March.)

\section{Correction}

\section{Anaesthetic awareness}

An editorial error occurred in this letter by Drs $\mathrm{J} \mathrm{N}$ Lunn and $M$ Rosen (7 April, p 938). The recommendation is that the end tidal concentration of the volatile agent should be maintained at 0.6 minimal alveolar concentration and not $0.6 \%$ as published. 